\title{
Endocardial fibroelastosis in children with special reference to the lesions of cardiac ganglia
}

\author{
ALBINA ŻÓŁTOWSKA \\ From the Department of Morbid Anatomy, Gdánsk Medical Academy, Poland
}

SYNOPSIS In all cases of primary endocardial fibroelastosis investigated diffuse degenerative changes in the ganglion cells were detected. Thickened endocardium was formed by the proliferation of mesenchymal cells located under the endothelial endocardium and of the mesenchyme surrounding the necrobiotic muscle cells. In some cases 'axial' vacuolar degeneration, necrobiosis, and necrosis of muscle celis, interstitial oedema, and dilatation of capillaries and lymphatic spaces were found in the whole myocardium. In all cases these changes were in the subendocardial layer.

In the cases discussed morphological changes in the endocardium were seen to be secondary to lesions in myocardial and possibly in neural structures.

Morphological changes in cardiomyopathy with endocardial fibroelastosis have been the subject of many studies (Andersen and Kelly, 1956; Kelly and Andersen, 1956; Black-Schafer, 1957; Boj and Pikiel, 1964). The pathogenesis of this syndrome, however, has not as yet been explained. Some authors have recently stressed the role of the parasympathetic nervous cardiac system in the pathogenesis of certain heart diseases (Köberle, 1959; James and Reynolds, 1963; James, 1967). In this study changes in cardiac neural structures in cardiomyopathy with endocardial fibroelastosis were studied.

\section{Material and Method}

The material was from 17 children, aged from 4 months to 2 years, who had died of cardiomyopathy with endocardial fibroelastosis. The control group comprised seven children of the same age who had died from other causes. Postmortem examinations were performed eight to 36 hours after death.

For microscopic examination single sections from both ventricles were taken, while the complete atria were examined. The walls of the right and left atrium, including a part of the cardiac base, were cut horizontally into $0.3 \mathrm{~cm}$ sections which were fixed in $10 \%$ aqueous formol solution, processed routinely, and embedded in paraffin wax.

The sections were stained with haematoxylin and Received for publication 2 July 1970. eosin, Mallory's phosphotungstic acid haema toxylin (PTAH), Verhoeff's elastic stain, MacManus periodic-acid-Schiff (PAS), Masson's trichrome, Gomori's reticulum stain, and cresyl echt violet for Nissl substance.

\section{Clinical Data}

As can be seen in Table I the age span of the patients was from 4 to 24 months. There were two cases of sudden death, two cases of clinically diagnosed myocarditis, three of pneumonia, and one case of leptomeningitis. In three cases death was preceded by respiratory and in the remaining cases by circulatory insufficiency.

\section{Results}

GROSS APPEARANCE OF THE HEART

The macroscopic outline of the heart in all cases of cardiomyopathy with endocardial fibroelastosis was similar. The heart was enlarged in all its dimensions, a ball-like, rounded apex formed by the left ventricle. The left ventricle was wide, the septum protruding toward the right, the heart muscle hypertrophic. The endocardium of the left ventricle was porcelain white, thick, and in two cases the endocardium of the right ventricle was also thickened.

In three cases the endocardium was greyish-yellow and only focally greyish-white, and on cross- 


\begin{tabular}{|c|c|c|c|c|}
\hline Case & Age & $\operatorname{Sex}$ & Clinical Diagnosis & Pathological Diagnosis \\
\hline $\begin{array}{l}1 \\
2\end{array}$ & $\begin{array}{l}7 \mathrm{mth} \\
8 \mathrm{mth}\end{array}$ & $\begin{array}{l}\mathbf{F} \\
\mathbf{F}\end{array}$ & Sudden death & Oedema of the lungs, endocardial fibroelastosis \\
\hline 3 & $5 \mathrm{mth}$ & $\mathbf{M}$ & Acute myocarditis & Endocardial fibroelastosis, interstitial macrophagic pneumonia \\
\hline 4 & $6 \mathrm{mth}$ & $\mathbf{F}$ & Acute myocarditis and pneumonia & Purulent pneumonia, endoca-dial fibroelastosis \\
\hline 5 & $18 \mathrm{mth}$ & $\mathbf{M}$ & Interstitial pneumonia & $\begin{array}{l}\text { Endocardial fibroelastosis, adrenal hypoplasia, congenital cysts of } \\
\text { the lungs }\end{array}$ \\
\hline 6 & $4 \mathrm{mth}$ & $\mathbf{M}$ & Multifocal pneumonia & Endocardial fibroelastosis, catarrhal pneumonia \\
\hline 7 & $1 \mathrm{yr}$ & $\mathbf{M}$ & & \\
\hline 8 & $13 \mathrm{mth}$ & $\mathbf{F}$ & Death in acute respiratory insufficiency & Endocardial fibroelastosis, congestion of the lungs \\
\hline 9 & $6 \mathrm{mth}$ & $\mathbf{M}$ & & \\
\hline 10 & $6 \mathrm{mth}$ & $\mathbf{M}$ & Leptomeningitis & Purulent leptomeningitis, endocardial fibroelastosis \\
\hline 11 & $2 \mathrm{yr}$ & $\mathbf{F}$ & & \\
\hline 12 & $9 \mathrm{mth}$ & $\mathbf{F}$ & & \\
\hline 13 & $6 \mathrm{mth}$ & $\mathbf{F}$ & & \\
\hline 14 & $18 \mathrm{mth}$ & $\mathbf{M}$ & Death in acute circulatory insufficiency & Endocardial fibroelastosis \\
\hline 15 & $8 \mathrm{mth}$ & $\mathbf{M}$ & & \\
\hline 16 & $4 \mathrm{mth}$ & $\mathbf{M}$ & & \\
\hline 17 & $1 \mathrm{yr}$ & $\mathbf{M}$ & & \\
\hline
\end{tabular}

Table Summary of clinical and pathological data

section it was a homogeneous, damp, greyish-yellow layer from $0 \cdot 1$ to $0 \cdot 2 \mathrm{~cm}$ thick, spreading under the entire endocardium of the left ventricle and of the septum of the right ventricle sharply contrasting from the rest of the greyish-pink myocardial layer. The trabeculary and papillary muscles in the entire cross section or only subendocardially were greyish yellow.

MICROSCOPIC APPEARANCE OF ENDOCARDIUM AND HEART MUSCLE

In sections stained with haematoxylin and eosin in all cases of investigated cardiomyopathy the thickened endocardium in the surface layer of the subendocardium contained for the most part slightly elongated cells with ovular nuclei and granularly distributed chromatin. In the deeper layer, however, spindle-shaped cells with cylindrical nuclei and evenly distributed chromatin were found. These cells were often wavy (Figs. 2 and 3 ). They were stained by the PTAH method a dark blue. Along these cells numerous thin and thick fibres, stained pink by eosin, were seen. Both the thin and thick fibres as well as the long axes of the observed cells usually ran parallel to the subendocardial layer (Figs. 3 and 4). All the fibres were stained deep violet-red in the PAS reaction. In sections stained by the classical Verhoeff method the thin fibres were stained red, while the thick ones turned brown. The whole of the thickened endocardium showed a network of argyrophilic fibres (Fig. 5).

Also in the altered endocardium single myocardial cells were PAS positive and appeared well preserved (Fig. 6). In the subendocardial layer, particularly between the trabeculae, were found spindleshaped cells and homogeneous membranes around the necrobiotic myocardial cells. In this layer the myocardial cells were swollen, the sarcoplasm around the nucleus was rarefied, and the remaining myofibrils on the perimeter had a distinct outline. Some of the cells had no nuclei and no sarcoplasm, and there were remnants of sarcolemma on their perimeter (Fig. 7). In other cases swollen myocardial cells staining poorly and completely blurred myofibrils predominated. These cells lacked cross striations (Fig. 8). Such changes could be found focally in various microscopical fields. Around the changed cells of the myocardium there were cells with cylindrical nuclei (Figs. 7 and 8 ), and amorphous PAS-positive substance. In some cases throughout the heart foci predominated in which the myocardial cells were thin, as if empty of sarcoplasm, and spread out because of oedema and proliferation of interstitial tissue. This tissue showed widening of capillaries and tissue spaces lined with endothelium corresponding to lymphatic spaces. In some cases the outline of the muscle layers of the coronary arterioles was blurred and the endothelial cells protruded towards the lumen of the vessel. The veins and lymphatic spaces around the arteries were noticeably widened.

\section{MICROSCOPIC APPEARANCE OF GANGLION CELLS OF THE ATRIUM}

In the hearts with endocardial fibroelastosis ganglion cells of both large and small ganglia were degenerated. They were swollen with nuclei pressed to the side (Fig. 9), either vacuolated or pyknotic (Fig. 10). In many of the cells the greatly thickened cell membrane surrounded the granular degenerated cytoplasm (Fig. 11). Some ganglia had only cell shadows or empty spaces left where the cells had vanished, surrounded by a wreath of excessively proliferating amphycytes and fibroblasts (Fig. 12). Such cells were PAS negative and lacked tygroid.

In three cases there was a complete lack of nerve 


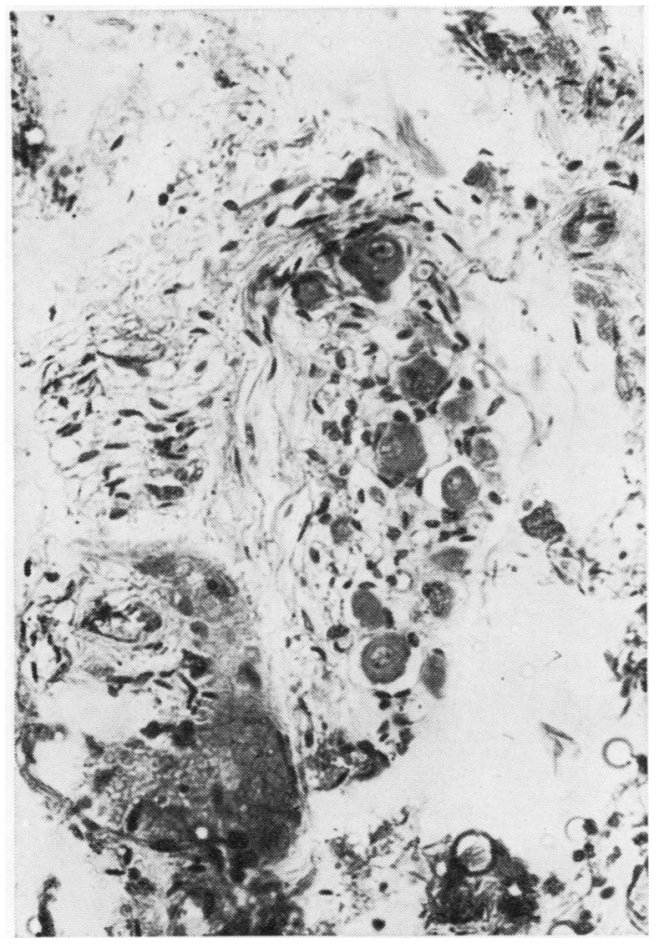

Fig. 1 Normal ganglia in atrium of 6-month-old infant. H.E. $\times 120$.

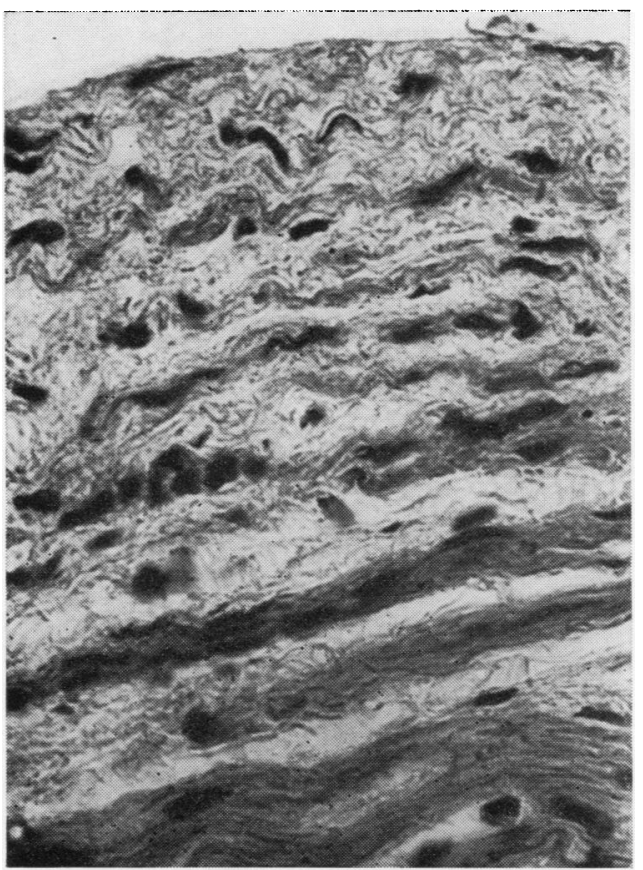

Fig. 2 Case 1. Fibres and cell structures laying parallel to the subendocardial layer of myocardium. H.E. $\times 380$.

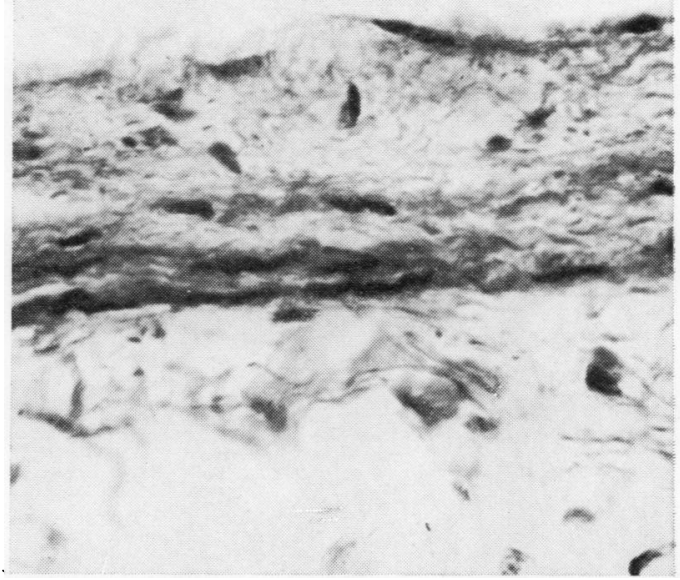

Fig. 3 Case 6. Wavy cells in thickened endocardium. H.E. $\times 400$.

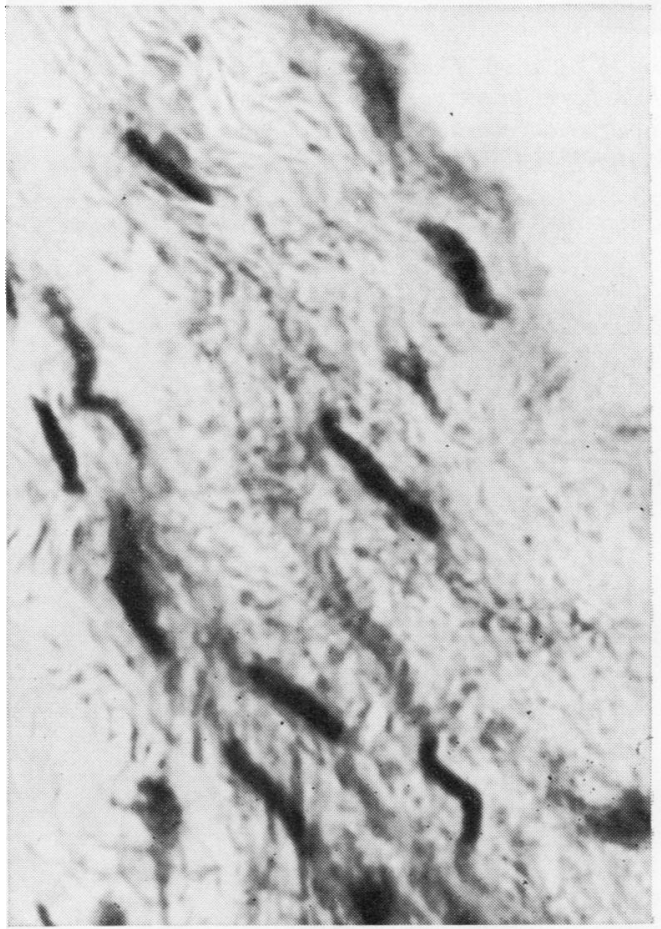

Fig. 4 Case 3. Spindle-shaped cells with cylindricai nuclei in thickened endocardium. H.E. $\times 480$. 


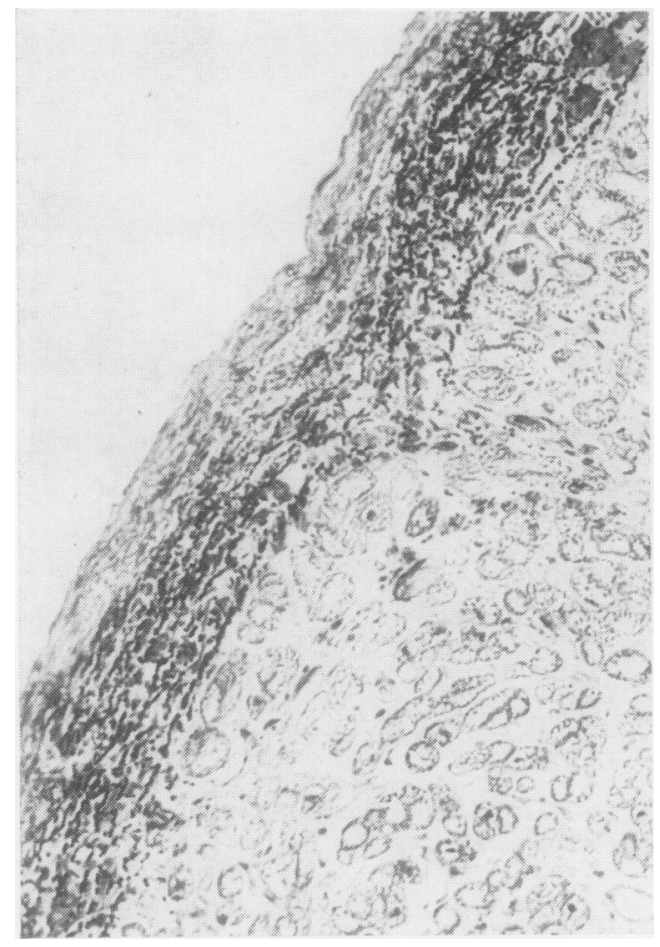

Fig. 5 Case 3. Thin fibres in the surface layer and thick fibres in the paramuscular layer. Axial vacuolar degeneration in the subendocardial layer. Verhoeff $\times 120$.

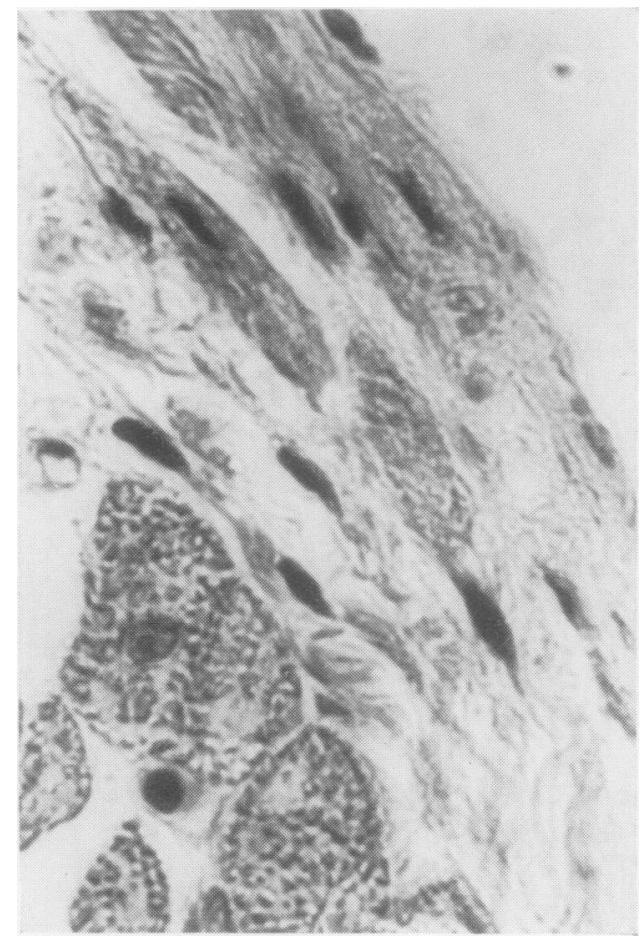

Fig. 6 Case 8. Single myocardial cells preserved in the thickened endocardium. H.E. $\times 480$.

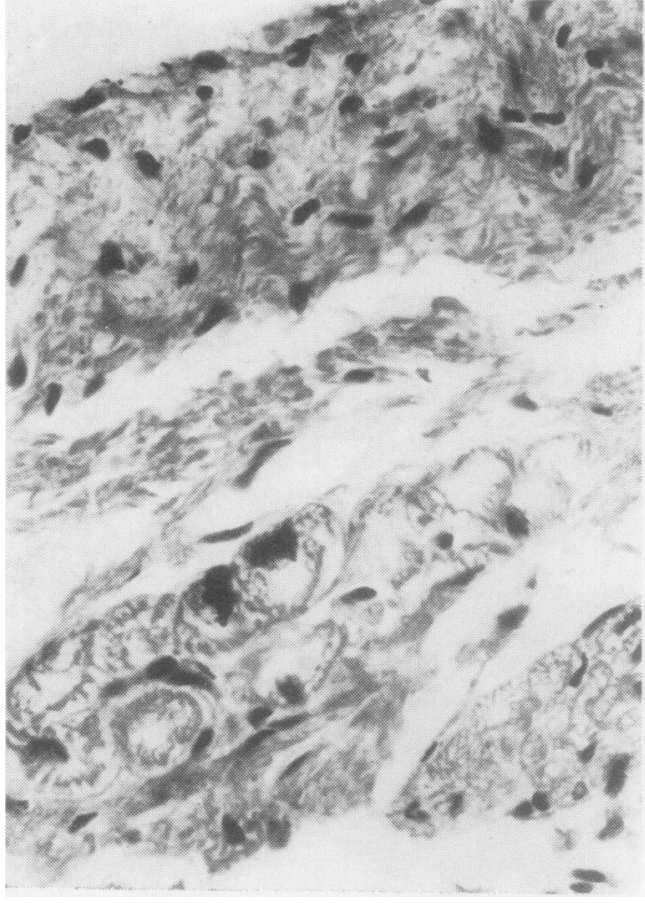

Fig. 7 Case 7. Muscle cells without nuclei and with rarefied sarcoplasm and vacuolar degeneration. H.E. $\times 300$.

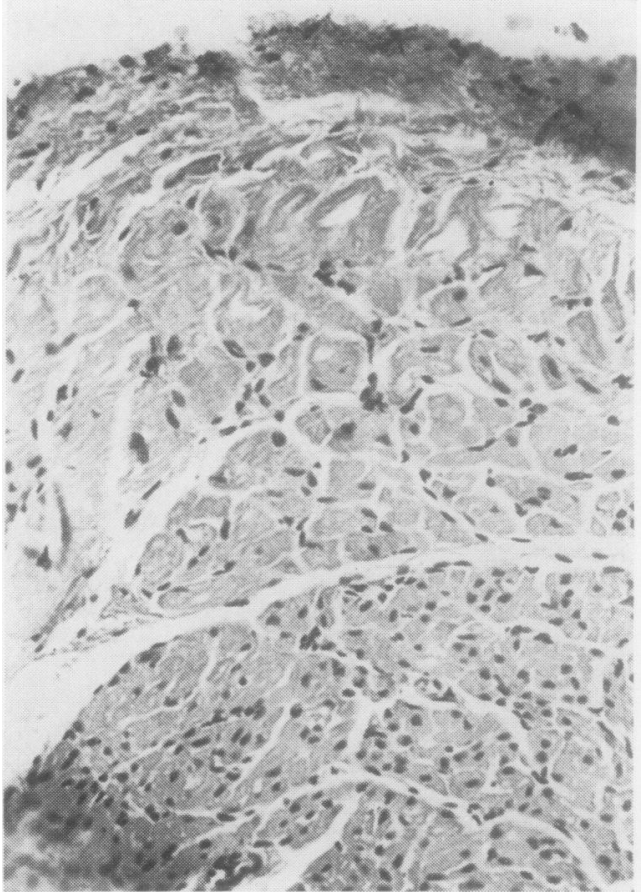

Fig. 8 Case 17. Heart muscle cells in subendocardial oedematous layer The outline of the myofibrils is blurred. Spindle-shaped cells around degenerated myocardial cells. H.E. $\times 120$. 


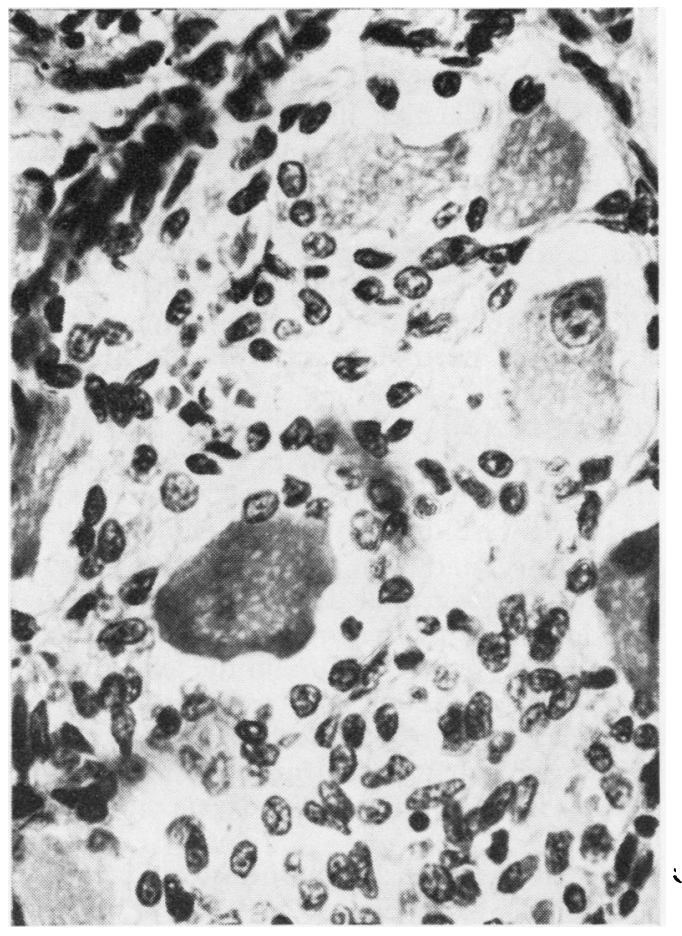

Fig. 9 Case 3. Ganglion cells with neuroplasm not uniformly stained and the nucleus is pressed to the side. H.E. $\times 320$.

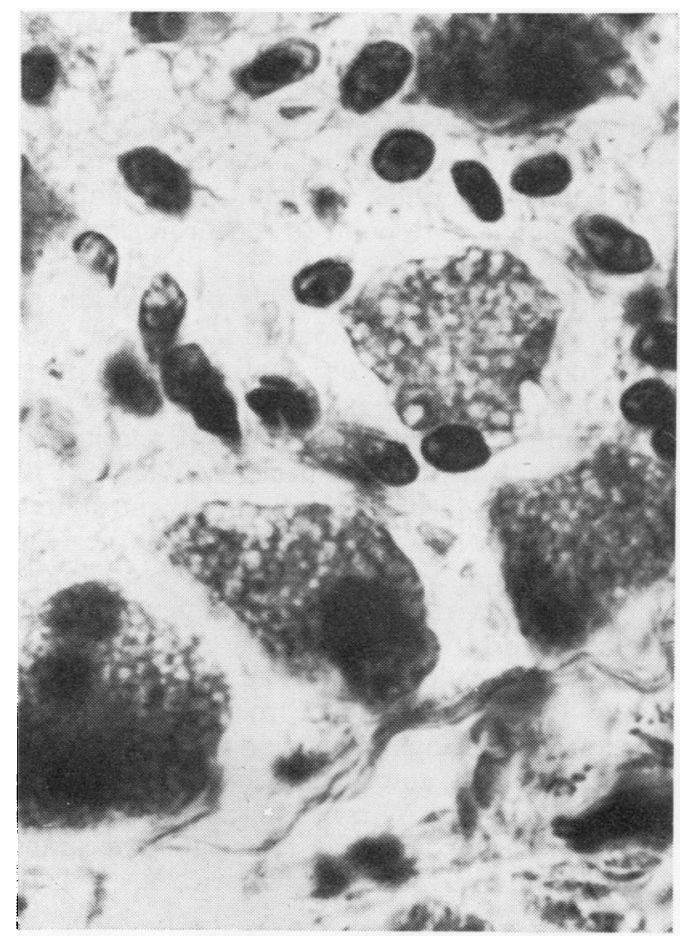

Fig. 10 Case 13. Vacuolated ganglion cells with pyknosis of nucleus. H.E. $\times 480$.

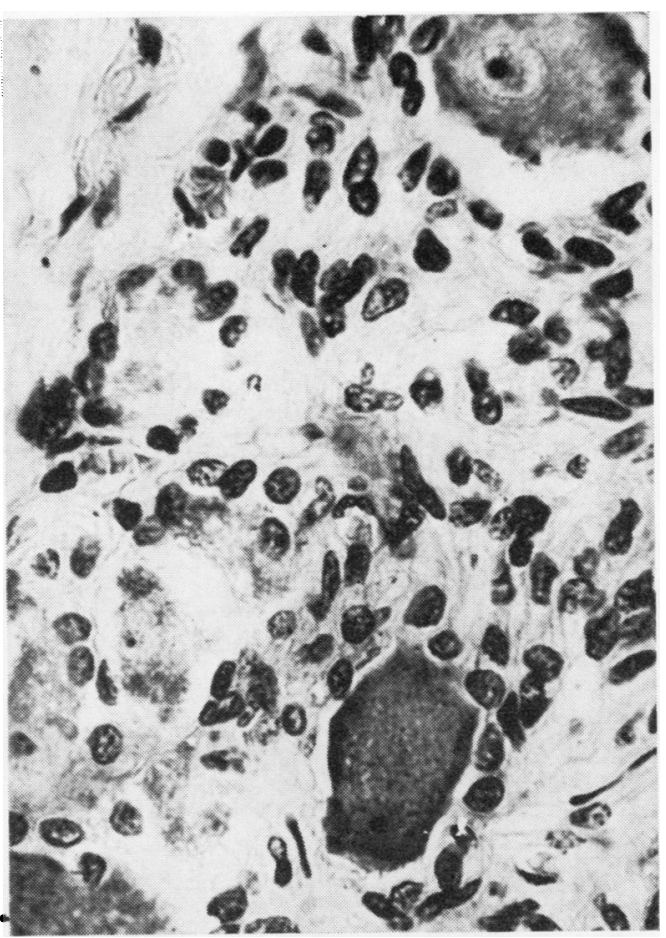

Fig. 11 Case 2. Ganglion cell with greatly thickened membrane surrounds granular degenerated cytoplasm. H.E. × 320 .

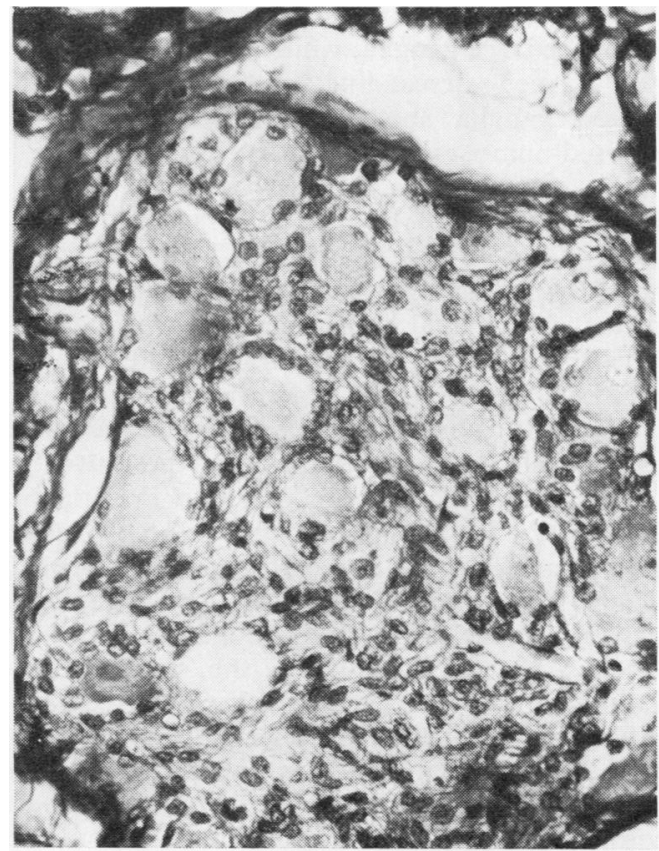

Fig. 12 Case 11. Cell shadows and empty spaces of vanished ganglion cells surrounded by wreath of excessively proliferating amphycytes and fibroblasts. H.E. $\times 160$. 


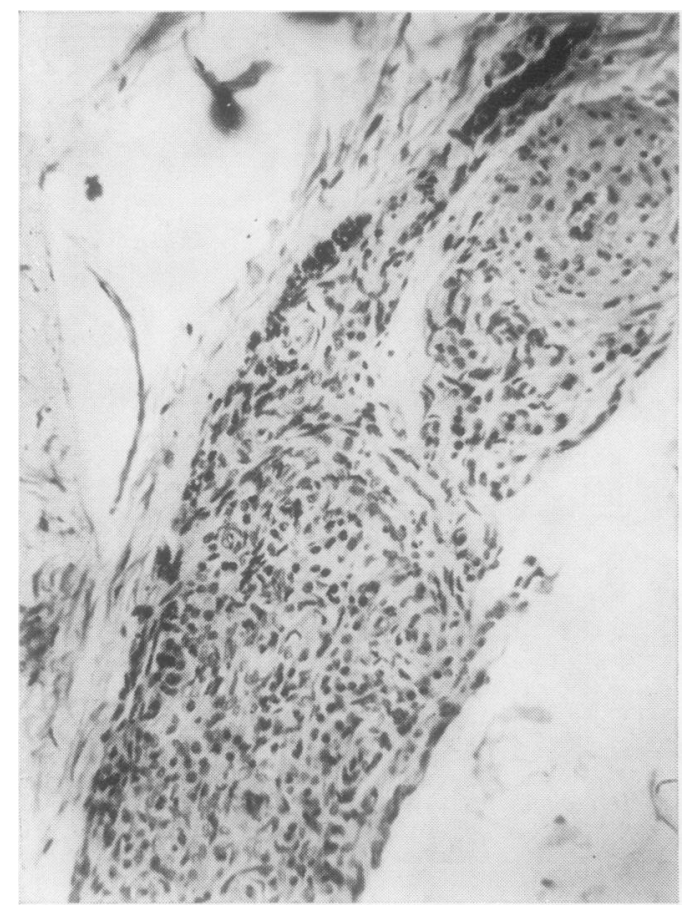

Fig. 13 Case 4. Ganglia lacking ganglion cells with descending nodes formed by proliferating amphycytes. H.E. $\times 120$.

cells in the large ganglia, while hypertrophic amphycytes formed descending nodes (Fig. 13). The changed ganglia showed mononuclear cells and increased numbers of fibroblasts (Fig. 14).

\section{Discussion}

The microscopically thickened endocardium contained mesenchymal and other cells which, because of their morphological appearance and affinity to certain stains, resembled smooth muscle cells. The development of argyrophilic and elastic membranes was connected with the presence of these two types of cell. The results of our previous investigations (Źóltowska, 1964) suggest that elastic elements forming subendocardial membranes most probably develop from smooth myocytes. They are formed from a substance with an initial collagen-like staining property created possibly by the smooth muscle cells perhaps at the beginning of their existence, ie, at the time when they possessed the properties of young mesenchymal cells. Elastoplasia is conditioned by the dynamic factor responsible for rebuilding the internal layer and possibly by the work of contractile elements of the already mature myocyte.
The proliferation of cellular elements which play a role in thickening the endocardium comes from the mesenchyme found under the endothelial endocardium and has a pathology similar to that of the thickening of the internal membrane of the coronary arteries in children (Dock, 1946; Schornagel, 1956; Robertson, 1960; Żółtowska, 1964), as well as from the mesenchyme proliferating around the necrobiotic cells of the heart muscle. This suggests that dynamic factors play a decisive role in its creation.

In congenital heart defects in infants endocardial thickening is a consequence of haemodynamic disturbances resulting from the fundamental features of the defect and from abnormal development of the muscle. In congenital defects with arterial stenosis, in addition to the haemodynamic factor connected with much greater pressure in the left ventricle than in the aorta, there is also anoxia (Ganong, 1967). Similar factors play a decisive role in such other aetiological changes as inflammation, infarcts, or various forms of myocardial degeneration (Hudson, 1965).

Primary endocardial fibroelastosis in children is diagnosed when there are no valvular heart lesions, no inflammation, or no exactly defined myocardial degeneration (Mitchell, Froehlich, Banas, and Gilkeson, 1966). The results of our own investigations, as also those of other authors (Andersen and Kelly, 1956; Kelly and Andersen, 1956; Boj and Pikiel, 1964), show that even in the so-called primary endocardial fibroelastosis the endocardial changes are secondary to the myocardial damage. The process of cardiac cell necrosis is most intensive in the subendocardial layer, which is very rich in a special type of receptor (Coleridge, Coleridge, and Kidd, 1964), and changes in the ganglia may point to a neurological cause of the disease.

Normally in the atrial walls of an infant where death was due to pneumonia, for example, ganglion cells occur in large or small bunches or singly included in the nerve pathway. These are large cells with uniformly staining cytoplasm and a vesicular nucleus with a distinct nucleolus. Each cell is surrounded by a layer of satellite cells, no more than three or four in a single section. The nerve fibres with Schwann cells and thin collagen fibres with single fibroblasts in their environment form a fine, loose network (Fig. 1).

Hearts of children who had died of cardiomyopathy with endocardial fibroelastosis showed degeneration of ganglion cells or their atrophy with a proliferation of amphycytes and the formation of descending nodes. These changes were accompanied by hyperplasia of fibroblasts and the appearance of a scanty number of mononuclear cells. 


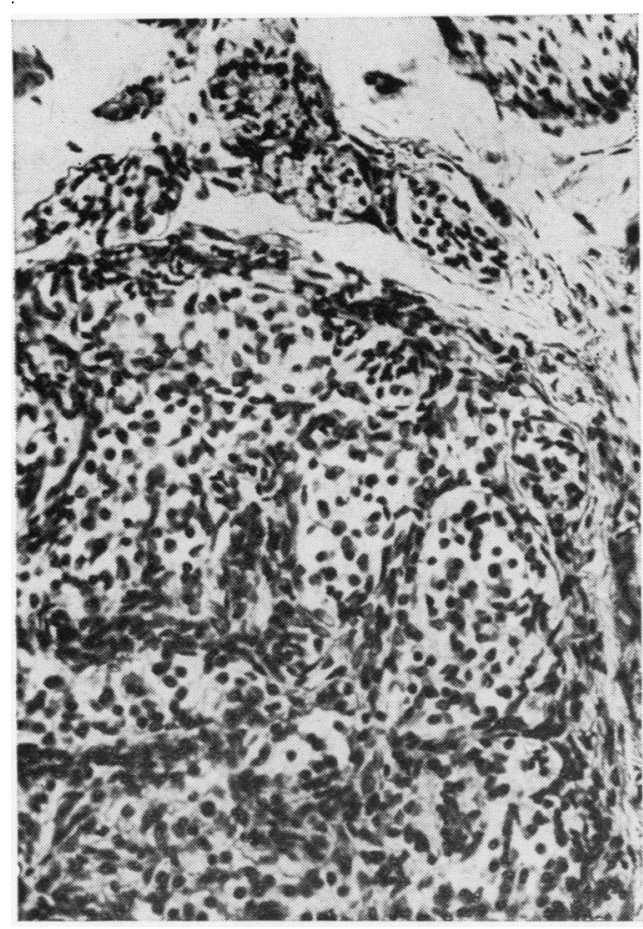

Fig. 14 Case 14. Ganglia lacking ganglion cells with spreading amphycytes, fibroblasts, and mononuclear cells H.E. $\times 160$.

The problem of the nervous control of the heart action is an open matter. Morphological (Hirsch and Borghard-Erdle, 1961; James, 1967) as well as biochemical (Burn and Rand, 1965; James, 1966; Malmfors, 1967) studies show the importance of this system to the work of the heart. Electron micrographs of cardiac neural structures show the existence of vesicular structures, most probably morphological exponents of mediator transportation of the autonomic system. Indirect evidence of cholinergic innervation of the cardiac pacemaker may be obtained with stains for cholinesterase (James and Sherf, 1968). Although it is now assumed that the formation and conduction of impulses in the heart occur within specialized myocardial cells the function of these cells is under the control of the cardiac nervous system. All this shows that the optional activity of the heart depends on the synchronization of the pacemaker and the cardiac nervous system (James, 1967).
Morphological changes in the heart in the form of cardiomegaly may possibly depend on the degree of damage to the parasympathetic nervous system and are evidence of inefficient cardiac activity. Reconstruction of the endocardium, on the other hand, may be a consequence of the dynamic factor also connected with high frequency of impulses in this layer, particularly in the case of dilatation (Coleridge $e t$ al, 1964). The problem of whether changes in the nerve elements precede the cardiac hypertrophy and endocardial thickening found later can be solved only by further experiments on animals.

\section{References}

Andersen, D. H. and Kelly, J. (1956). Endocardial fibro-elastosis. I. Endocardial fibro-elastosis associated with congenital malformations of the heart. Pediatrics, 18, 513-538.

Black-Schaffer, B. (1957). Infantile endocardial fibroelastosis. A suggested etiology. Arch. Path., 63, 281-306.

Boj, E., and Pikiel, L. (1964). Contribution to pathogenesis of endocardial fibroelastosis in children.-(Polish.) Acta biol. med. (Gdanisk), 8, 1-9.

Burn, J. H., and Rand, M. J. (1965). Acetylcholine in adrenergic transmission. Ann. Rev. Pharmacol., 5, 163-182.

Coleridge, H. M., Coleridge, J. C. G., and Kidd, C. (1964). Cardiac receptors in the dog, with particular reference to two types of afferent ending in the ventricular wall. J. Physiol. (Lond.), 174, 323-339.

Dock, W. (1946). The predilection of atherosclerosis for the coronary arteries. J. Amer. med. Ass., 131, 875-878.

Ganong, W. F. (1967). Coronary circulation. In Review of Medical Physiology, 3rd ed., pp. 491-493. Lange, Los Altos, California.

Hirsch, E. F., and Borghard-Erdle, A. M. (1961). The innervation of the human heart. I. The coronary arteries and the myocardium. Arch. Path., 71, 384-407.

Hudson, R. E. B. (1965). Endocardial fibrosis. In Cardiovascular Pathology, vol. 1, pp. 863-877. Arnold, London.

James, T. N. (1966). Cholinergic mechanisms in the sinus node with particular reference to the actions of hemicholinium. Circulat. Res., 19, 347-357.

James, T. N. (1967). Cardiac innervation: anatomic and pharmacologic relations. Bull. N.Y. Acad. Med., 43, 1041-1086.

James, T. N., and Reynolds, E. W., Jr. (1963). Pathology of the cardiac conduction system in a case of diphtheria associated with atrial arrhythmias and heart block. Circulation, 28, 263267.

James, T. N., and Sherf, L. (1968). Ultrastructure of myocardial cells. Amer. J. Cardiol., 22, 389-416.

Kelly, J., and Andersen, D. H. (1956). Congenital endocardial fibroelastosis. II. A clinical and pathologic investigation of those cases without associated cardiac malformations including report of 2 familial instances. Pediatrics, 18, 539-555.

Köberle, F. (1959). Cardiopathia parasympathicopriva. Münch. med. Wschr., 101, 1308-1310.

Malmfors, T. (1967). Fluorescent histochemical studies on the uptake, storage, and release of catecholamines. Circulat. Res., 20-21, Suppl., III, 25-42.

Mitchell, S. C., Froehlich, L. A., Banas, J. S., Jr., and Gilkeson, M. R. (1966). An epidemiologic assessment of primary endocardial fibroelastosis. Amer. J. Cardiol., 18, 859-866.

Robertson, J. H. (1960). Stress zones in foetal arteries. J. clin. Path., 13, 133-139.

Schornagel, H. E. (1956). Intimal thickening in the coronary arteries in infants. Arch. Path., 62, 427-432.

Zóttowska, A. (1964). Genesis of focal thickening of children's coronary arteries in the light of morphological examination. (Polish.) Acta biol. med. (Gdańsk), 8, 11-23. 